Corrigendum

\title{
Corrigendum to "Neurogenesis and Increase in Differentiated Neural Cell Survival via Phosphorylation of Akt1 after Fluoxetine Treatment of Stem Cells"
}

\author{
Anahita Rahmani, ${ }^{1}$ Danial Kheradmand, ${ }^{2}$ Peyman Keyhanvar, ${ }^{3,4}$ \\ Alireza Shoae-Hassani, ${ }^{1}$ and Amir Darbandi-Azar ${ }^{4}$ \\ ${ }^{1}$ Stem Cell and Tissue Engineering Department, Research Center for Science and Technology in Medicine (RCSTiM), \\ Tehran University of Medical Sciences, Tehran, Iran \\ ${ }^{2}$ Faculty of Medicine, Islamic Azad University, Mashhad Branch, Mashhad 19988-96953, Iran \\ ${ }^{3}$ Medical Nanotechnology Department, School of Advanced Technologies in Medicine, \\ Tehran University of Medical Sciences, Tehran, Iran \\ ${ }^{4}$ Rajaei Cardiovascular, Medical, and Research Centre, Iran University of Medical Sciences, P.O. Box 14185-615, Tehran, Iran \\ Correspondence should be addressed to Amir Darbandi-Azar; nanobiotechnology@ymail.com
}

Received 13 December 2014; Accepted 24 December 2014

Copyright (C) 2015 Anahita Rahmani et al. This is an open access article distributed under the Creative Commons Attribution License, which permits unrestricted use, distribution, and reproduction in any medium, provided the original work is properly cited.

In "Neurogenesis and Increase in Differentiated Neural Cell Survival via Phosphorylation of Akt1 after Fluoxetine Treatment of Stem Cells," there was an error in Figure 4(a), and here we provide the right form of Figure 4(a). 

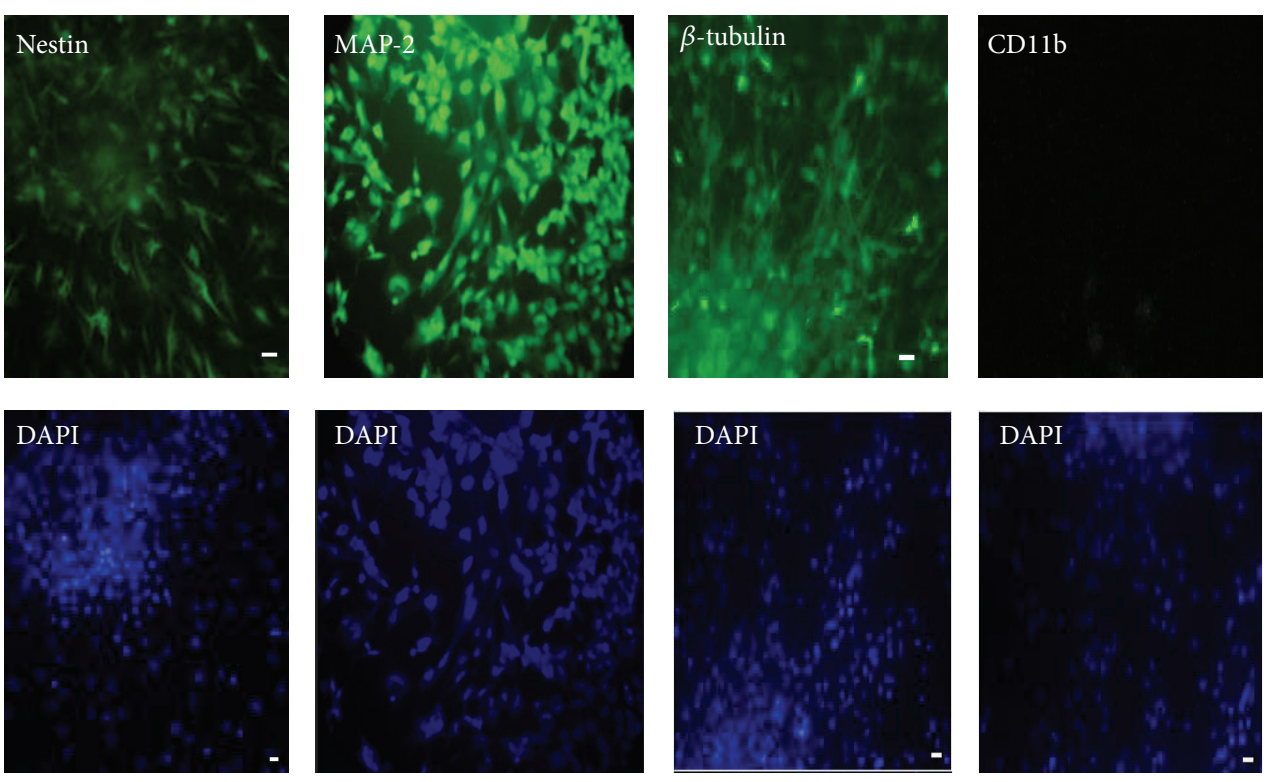

(a)
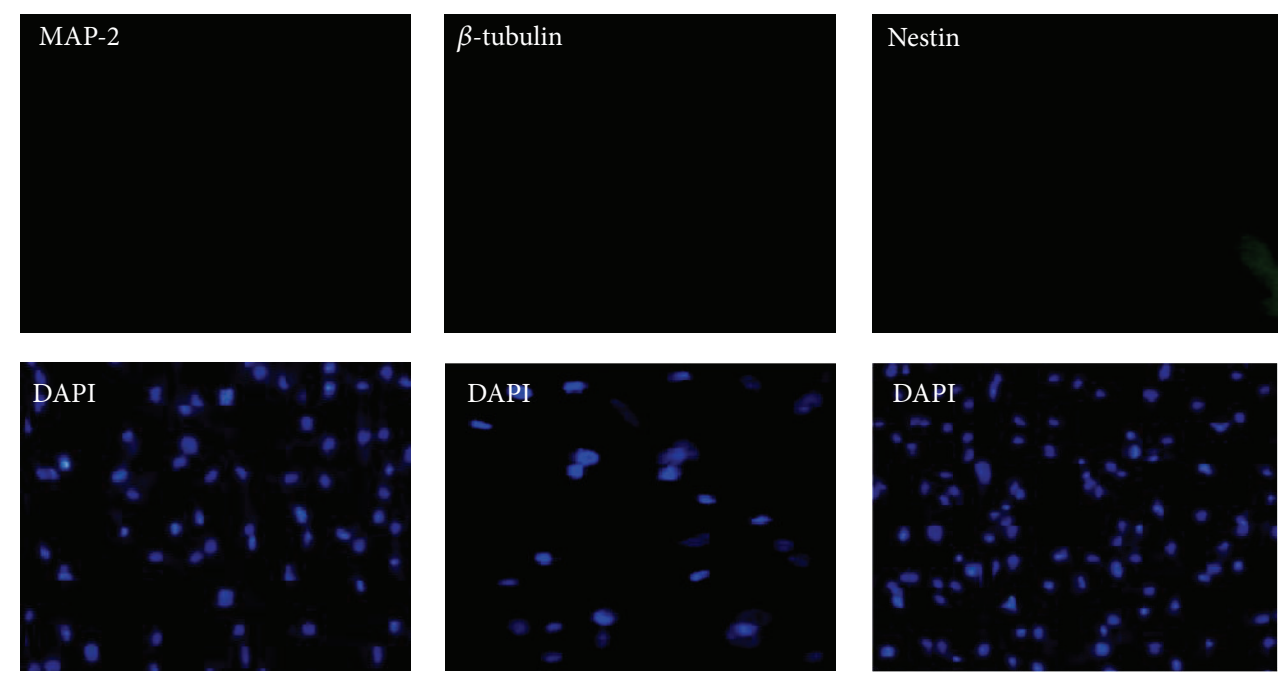

(b)

FIGURE 4: Immunostaining of hEnSCs differential markers. Expression of neuron markers including Nestin, MAP-2, and $\beta$-tubulin was analyzed in FLX induced differentiation after $10 \mathrm{~d}$. The expression of CD11b as a glial marker was not obvious. The size bar is $10 \mu \mathrm{m}$ (a). Immunostaining of LY294002 treated hEnSCs after culture in FLX supplemented medium. There is not an expression of neuron markers in FLX induced differentiation after $10 \mathrm{~d}$ (b). 

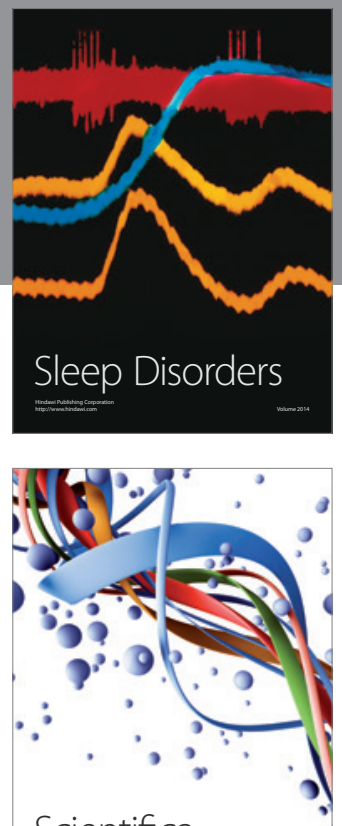

Scientifica
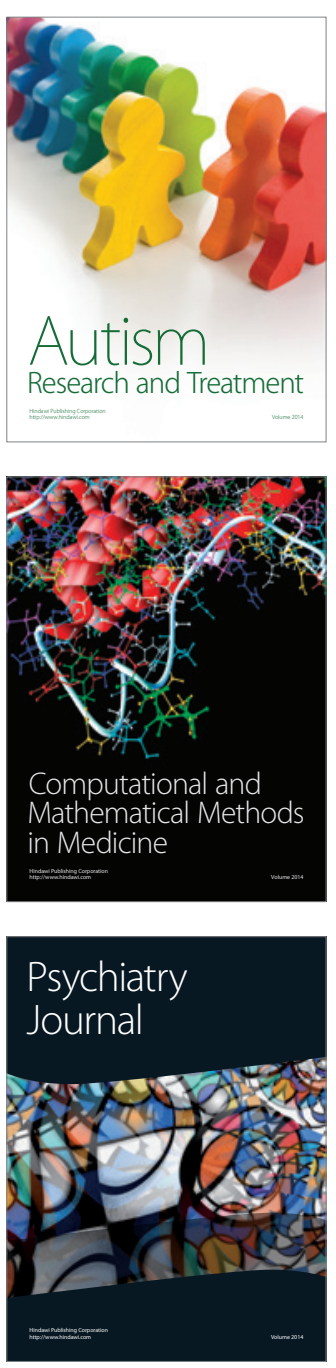
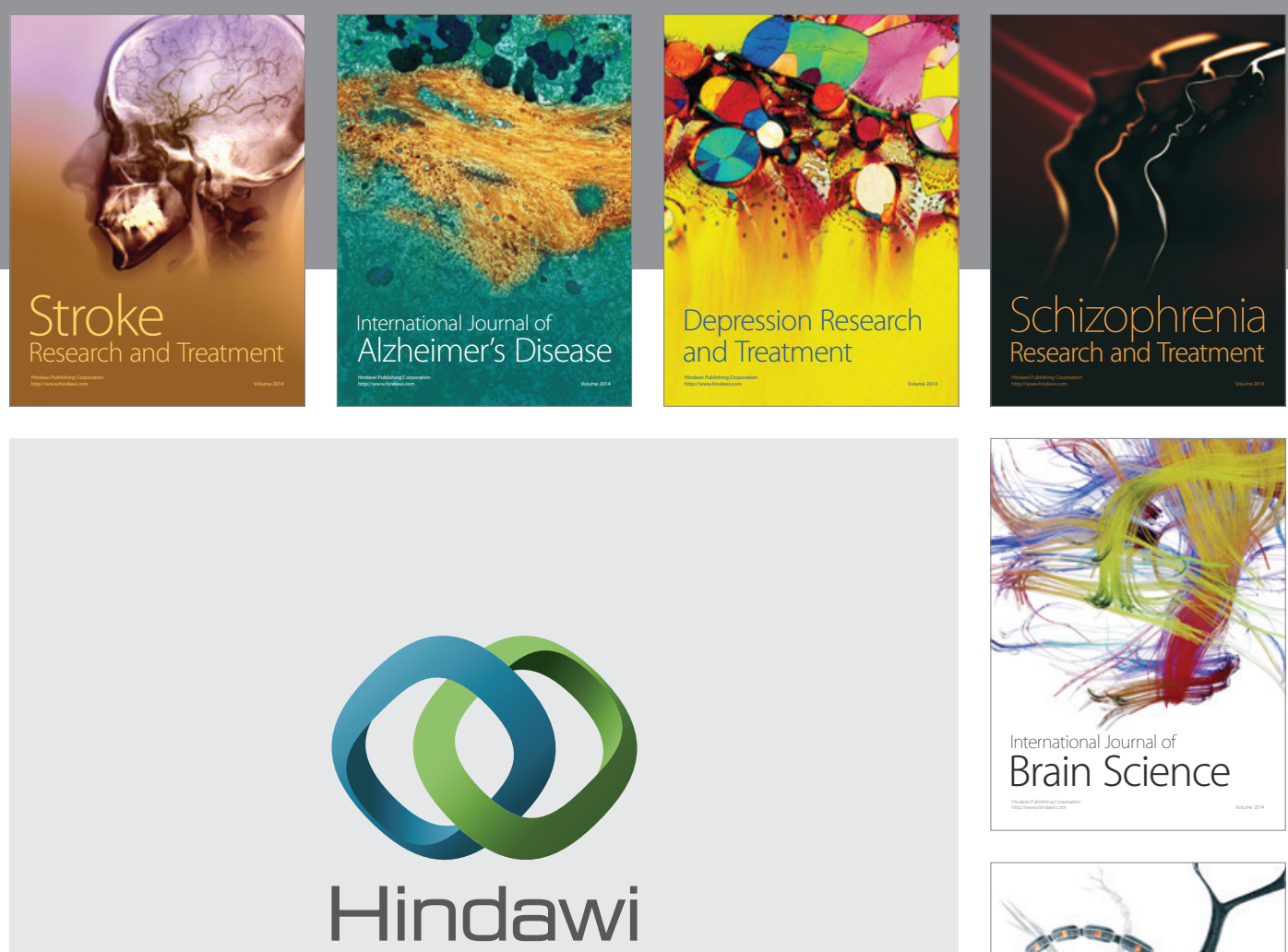

Submit your manuscripts at

http://www.hindawi.com
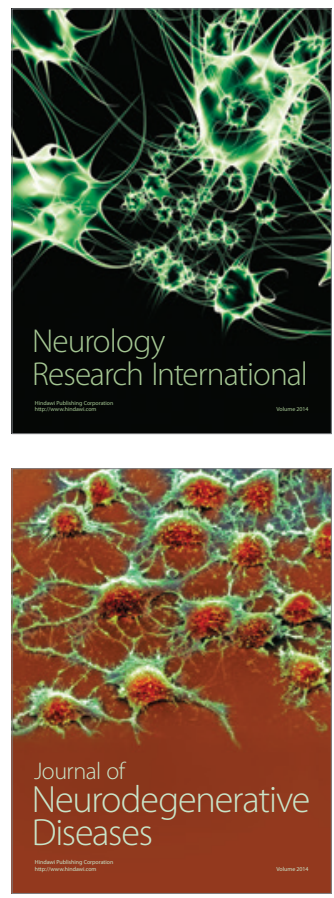

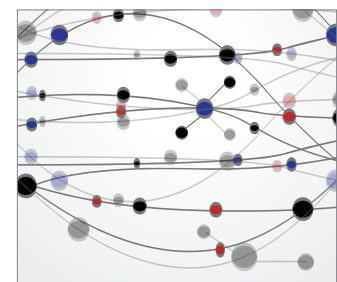

The Scientific World Journal
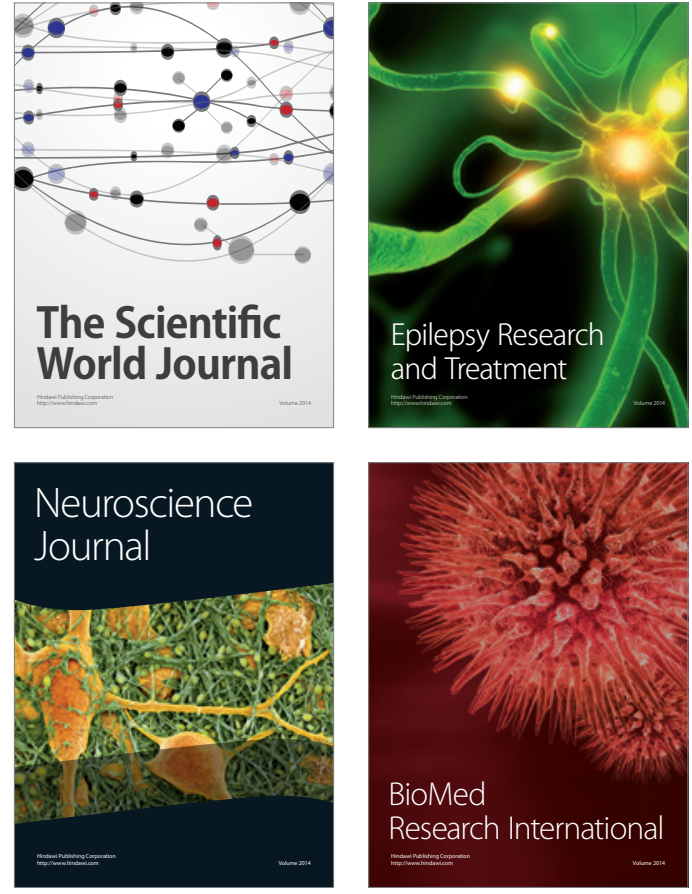

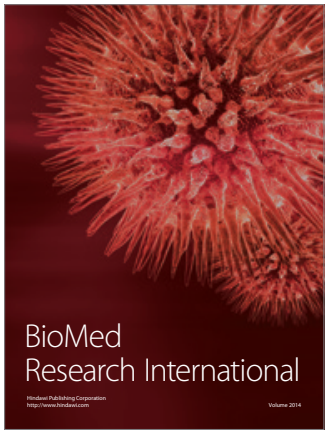

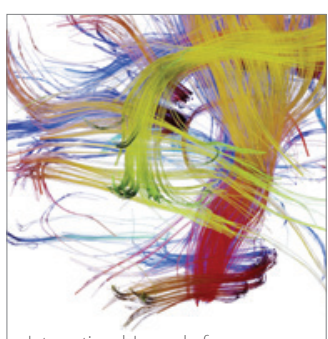

Brain Science

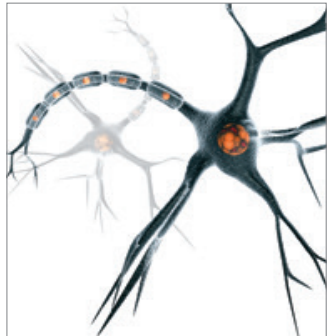

Neural Plasticity
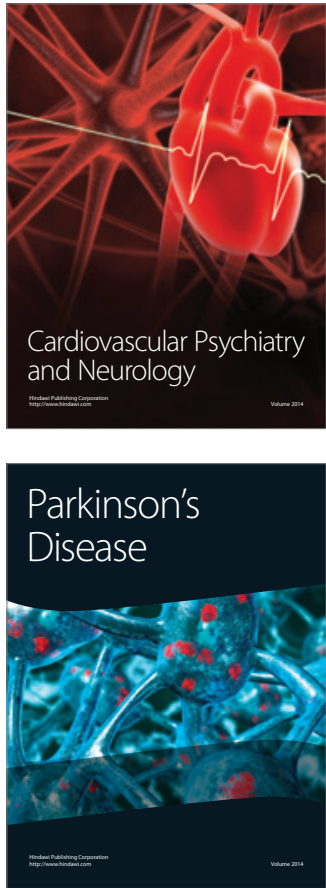